\title{
Design and Fabricate a Continuous Pork Roaster using Infrared Heating
}

\author{
Teerapot Wessapan and Theerapong Borirak \\ Department of Mechanical Engineering, Eastern Asia University, Pathumthani, Thailand \\ teerapot@yahoo.com, t_borirak@eau.ac.th
}

\begin{abstract}
Roasted pork is a favorite dish in many different cultures, and countries. At present, the roasting process is highly polluting, emitting high carbon dioxide loads to atmosphere, particulate pollution that can pollute the surrounding environment. An electric roaster is just as suitable for roasting the pork with low pollution and high efficiency but it has slow cooking capacities. So, the objectives of this research are to design and fabricate a continuous pork roaster using infrared heating for community enterprises, with its capacity and efficiency should be in an acceptable range. The designed roaster is used for production of roasted pork. The experiments are carried out on a continuous pork roaster using infrared heating. Three kilograms of pork meat are applied with the 3 infrared heaters with the power of $1000 \mathrm{~W}$ each that give a maximum of $3000 \mathrm{~W}$. Capacity test results show that the production capacity of the roaster is approximately 400 pieces $/ \mathrm{hr}$ continually. And the surface of roasted pork obtained from this roaster meet the community product standard. Therefore, if small and micro community enterprises are persuaded to use the developed roaster, it can reduce pollution from roasting process and help keep our air and environmental clean. This technology also helps to reduce cost and production time, and improve productivity, and eventually lead to be able to survive in competitive environments.
\end{abstract}

Index Terms - Roaster, Infrared Heating, Pork, Pollution, Environment

\section{Introduction}

Roasting is a cooking method that is typically reserved for superior cuts of meat like beef tenderloins, rib roasts, loins of pork and so on. Roasting is a cooking method that uses dry heat, whether an open flame, oven, or other heat source. Roasting can enhance flavor through caramelization and Maillard browning on the surface of the food. Roasting uses indirect, diffused heat (as in an oven), and is suitable for slower cooking of meat in a larger, whole piece. Pork and most root and bulb vegetables can be roasted. Roasted pork (Fig. 1) is a favorite dish in many different cultures, and countries.

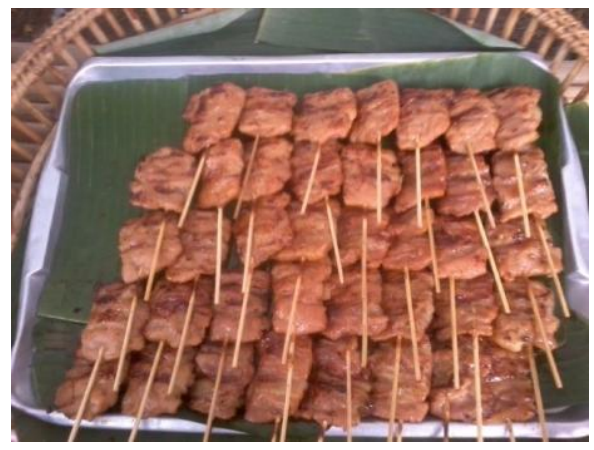

Fig. 1 The roasted pork.
At present, the pork roasting process (shown in Fig. 2) is highly polluting, emitting high carbon dioxide loads to atmosphere, particulate pollution that can pollute the surrounding environment. An infrared roaster is just as suitable for roasting the pork with low pollution and high efficiency. Moreover, a lesser known fact is that conventional roasting with hot air and infrared roasting techniques yield very different results in roasting quality. However the infrared roasting has slow cooking capacities.

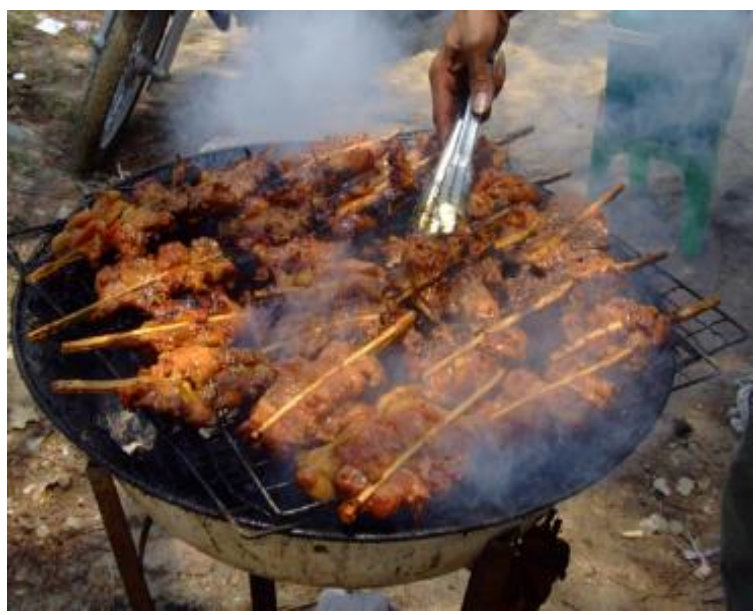

Fig. 2 The traditional roasting method.

Infrared (IR) radiation is electromagnetic radiation with longer wavelengths than those of visible light, extending from the nominal red edge of the visible spectrum at 0.74 micrometres $(\mu \mathrm{m})$ to $300 \mu \mathrm{m}$. Infrared radiation is more rapid in heat transfer than convection and conduction mechanisms and has been found to be more effective heating compared to conventional process [1-5]. So, the objectives of this research are to design and fabricate a continuous pork roaster using infrared heating for community enterprises, with its capacity and efficiency should be in an acceptable range.

\section{Design and Fabricate a Continuous Pork Roaster}

The concept in design of components of the continuous pork roaster to get more output with better quality, and with safer machine operation shows in Table 1. 
Table 1 The concept in design of each part of the roaster

\begin{tabular}{|c|l|}
\hline Part & \multicolumn{1}{|c|}{ The concept in design } \\
\hline $\begin{array}{c}\text { Infrared } \\
\text { heater }\end{array}$ & $\begin{array}{l}\text { The heater used in this work is infrared heater, } \\
\text { which transfers the heat energy most efficiently to } \\
\text { materials. The heater has a maximum power output of 1000 } \\
\text { W each with very fast response times. }\end{array}$ \\
\hline Gripper & $\begin{array}{l}\text { It is used for the rapid loading the raw pork and unloading } \\
\text { the roasted pork. }\end{array}$ \\
\hline Conveyer & $\begin{array}{l}\text { Chain conveyor systems are flexible and can easily be } \\
\text { twisted axially or made to follow tight lateral turns along } \\
\text { their routes. }\end{array}$ \\
\hline Motor & $\begin{array}{l}\text { Design a motor base, which is a base for mounting a motor } \\
\text { and put it in the secure position. The frame carries a } \\
\text { driving motor and mounting motor to machine. }\end{array}$ \\
\hline Tray & $\begin{array}{l}\text { The tray is designed to be fast and easy to take the roasted } \\
\text { pork out. }\end{array}$ \\
\hline
\end{tabular}

The structure of the designed roaster is simple, high mechanical strength, high thermal efficiency, safety, reliability, easy installation, easy to realize the characteristics of automation control. Mechanism of the continuous pork roaster shows in Fig. 3.

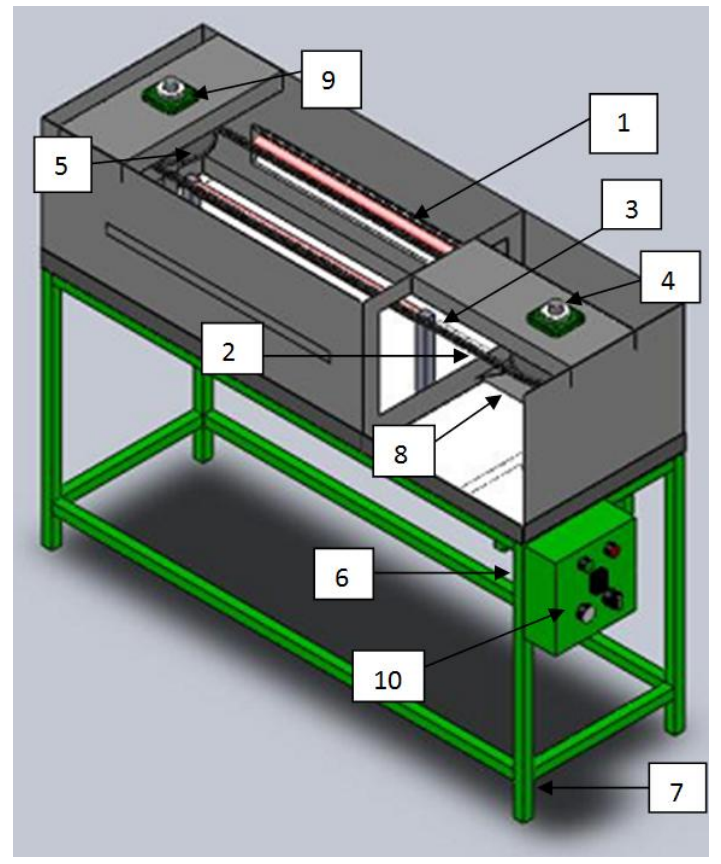

Fig. 3 Componets of the designed roaster.

Note: 1. infrared heater 2. Gripper 3. Conveyer 4. Shaft 5. sprocket wheel 6. Motor 7. Tripod 8. Tray 9. Bearing 10. controller

Fig. 4 shows the continuous pork roaster designed. For a design roaster that converts energy from electrical energy form into thermal energy of the raw material as a result of this rise in raw pork temperature. The thermal efficiency can be defined as:

$$
\eta t h \equiv \frac{Q_{\text {out }}}{Q_{\text {in }}}
$$

where the $Q$ quantities are heat-equivalent values.

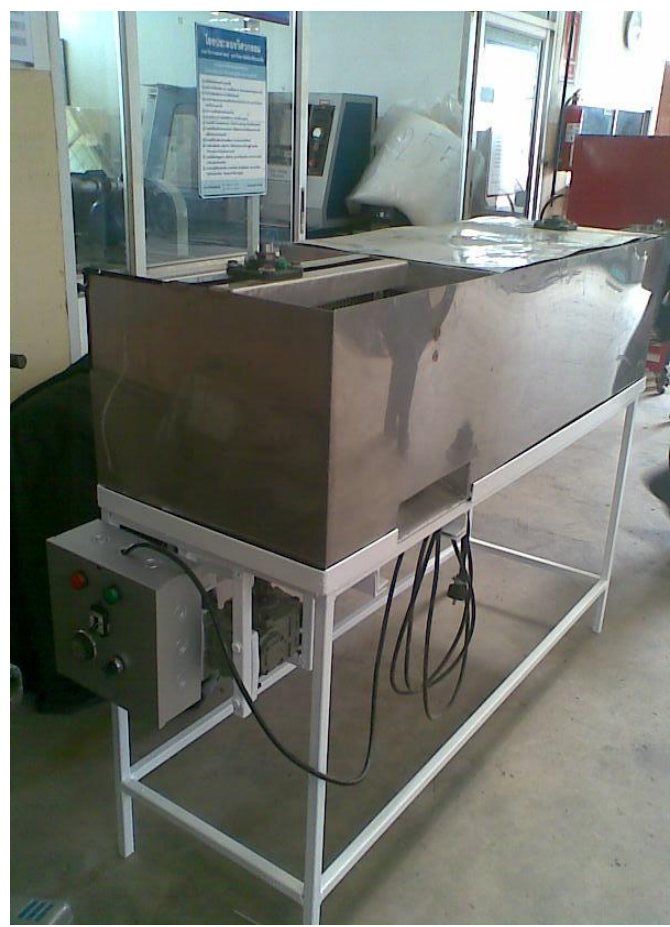

Fig. 4 The continuous pork roaster designed.

\section{Results}

The capacity test of the continuous pork roaster using infrared heating shown in Fig. 5. Results from the roast testing at motor speed $17 \mathrm{rpm}, 21 \mathrm{rpm}$, and $26 \mathrm{rpm}$ found that at the motor speed of $21 \mathrm{rpm}$, the result appear to be better appearance. It is show that the obtained capacity is independent of the motor speed as shown in Figure 6.

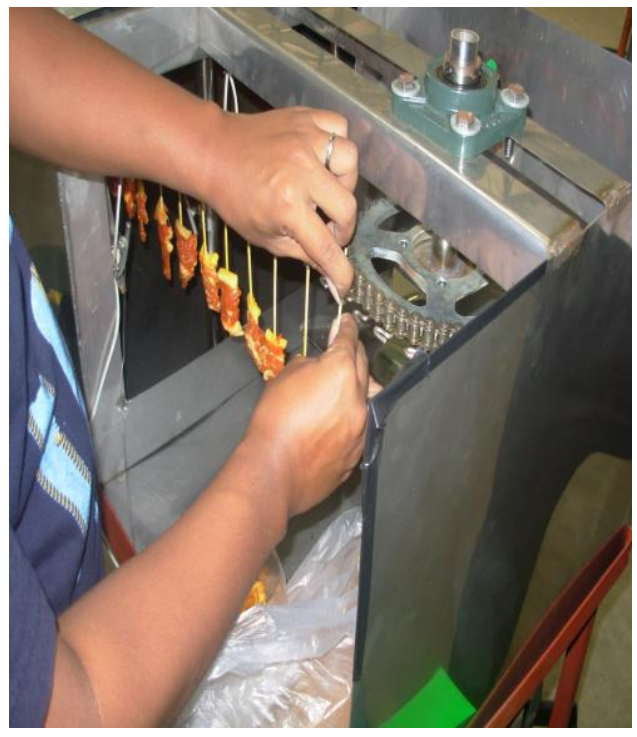

Fig. 5 Capacity test. 


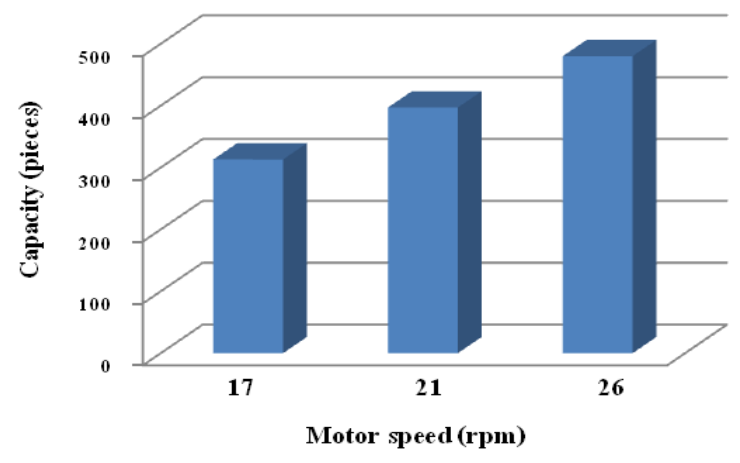

Fig. 6 Capacity test results.

raphs from Figure 7 shows that at a specified motor speed, the thermal efficiency of the roaster varies according to the operating temperature, the lower operating temperature the higher thermal efficiency. Therefore, if higher of the thermal efficiency is needed, the operating temperature must be adjusted to be lower.

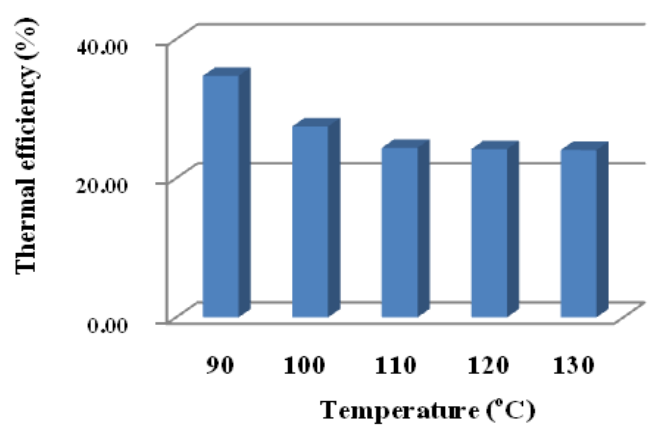

Fig. 7 Thermal efficiency of the roaster at various operating temperature at the motor speed of $21 \mathrm{rpm}$.

In cost analysis, raw pork is used as raw material which is available in market. In cost analysis for roasted pork production by using a designed roaster and one labor, it is assumed that the roaster have a useful life expectancy of 5 years, the operating time at 8 hours a day, 250 days in a year, direct labor cost per day is $10 \mathrm{USD} /$ labor, electricity cost of $0.1 \mathrm{USD} / \mathrm{kWh}$, total electrical input power is $3 \mathrm{~kW}$, briquette price is $0.2 \mathrm{USD} /$ piece, raw material cost and transportation cost is $0.1 \mathrm{USD} /$ piece. Price of the roaster is approximately 1,000 USD. The first investment is 5,000 USD, including the storehouse and facilities. The roaster average capability is approximately 100 pieces/hr. Results from the analysis show that, payback period for the production is approximately 3 months. The actual amount of energy consumption and amount of the roasted pork obtained depend on application of the unit.

\section{Discussion}

According to design and development of the roaster and the results of the functional and capacity testing, it found that the designed roaster can work functionally and properly with the obtained product quality is in an acceptable range.
The comparison between the new and the traditional roasting system shows that a lot of improvement occurred in the new system such as the process time, worker and production area required, operating cost, and productivity. It is so because combining all functions in a single unit and the machine can operate continually can help to reduce the transfer time and distance, and material. The new system just needs one worker to operate the roaster and convey the material. That leads to reduce cost and improve the productivity of the system.

The roaster has potential to replace the traditional roasting system in the market due to the low price of the roaster and its short payback period.

\section{Conclusions}

The compact continuous pork roaster using infrared heating fabricated for this research is a prototype unit. The continuous pork roaster, $25 \mathrm{~W}$ chain drive DC motor and 3 infrared heaters with the power of $1000 \mathrm{~W}$ each that give a maximum of $3000 \mathrm{~W}$ are used to produce roasted pork. Capacity test results show that the maximum production capacity of the roaster is about 400 pieces / $/ \mathrm{hr}$ continually. And the surface of roasted pork obtained from this roaster meet the community product standard. Price of a designed roaster is approximately 1,000 USD, rather low cost and use less workers. From comparison between the new and the existing/traditional roasting system, it is found that when using the roaster, the required production area, production time and operating cost are significantly reduced when using the roaster. Furthermore, the investment in producing roasted pork by using designed roasted, based on mentioned conditions, is economically attractive also with payback period of 3 months. Therefore, if small and micro community enterprises are persuaded to use the developed roaster, it can reduce pollution from roasting process and help keep our air and environmental clean. This technology also helps to reduce cost and production time, and improve productivity, and eventually lead to be able to survive in competitive environments.

\section{Acknowledgements}

The authors wish to express their sincere to Mr. Nattasak Pakawatsitanon, Mr. Sakda Thairuang, and Mr. Suriya Wangruamklang of the mechanical engineering department, Eastern Asia University for helping us with this research.

\section{References}

[1] H.U. Hebbar, K.H. Vishwanathan and M.N. Ramesh: Journal of Food Engineering Vol. 65 (2004), p. 557-563

[2] Z. Pan, C. Shih, T.H. McHugh and E. Hirschberg: Food Science and Technology Vol. 41 (2008), p. 1944-1951

[3] C. Shih, Z. Pan, T.H. McHugh, D. Wood, E. Hirschberg and D. Olson: Food Science and Technology Vol. 41 (2008), p. 1962-1972

[4] Y. Zhu and Z. Pan: Journal of Food Engineering Vol. 90 (4) (2009), p. $441-452$

[5] J. Yang, G. Ginglo, Z. Pan, M.T. Brandi, T.H. McHugh and H. Wang: Journal of Food Engineering Vol. 101 (2010), p. 273-280 